Language Switches in L3 Production: Implications for a Polyglot Speaking Model*

\author{
SARAH WILLIAMS and BJÖRN HAMMARBERG \\ Stockholm University
}

Manuscript September 1997

To appear in Applied Linguistics

Address:

Björn Hammarberg

Department of Linguistics

Stockholm University

S-10691 Stockholm, Sweden

Phone: +46 8162333

Fax: +468155389

E-mail: ham@ling.su.se 


\section{Language Switches in L3 Production: Implications for a Polyglot Speaking Model*}

In general, discussion of crosslinguistic influence has focussed almost exclusively on the role of L1 in L2 production, both in the form of crosslinguistic influence on the learner's interlanguage and in the form of language switches to the L1 during L2 production. As yet, there has been little work done on the influence of a learner's other previously learned L2s in the acquisition of a new language (L3). The few studies that have been been carried out on the role of L2 in L3 production however show that 22 does play an important role in L3 acquisition.

This paper presents the results of ongoing research on non-adapted language switches, using data from a 2 year longitudinal case study of an adult learner of L3 Swedish with L1 English and L2 German, both of which languages are related to Swedish. Our study is based on a corpus of 844 nonadapted language switches. We identified four main types of non-adapted language switch, 3 of which had pragmatic purpose, namely: i) EDIT (marking self-repair, beginning of turntake etc.), ii) META (used for asides, to comment on L3 performance or ask for help) and iii) INSERT (use of non-

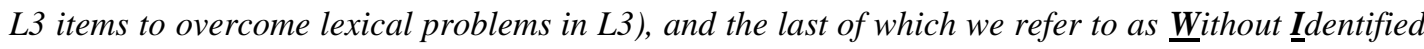
Pragmatic $\underline{\boldsymbol{P}}$ urpose (WIPP switch; cf. "non-intentional switches", Poulisse \& Bongaerts, 1994). We found that while both L1 English and L2 German occurred in EDIT and INSERT functions, it was only L1 English that occurred in META function and almost only L2 German that occurred in WIPP switches. Of these WIPP switches, the majority were function words. We also noticed that a number of the English utterances used in INSERT function appeared to show German influence, although this was not the case when English was used in META function.

Our results show that in this case study of L3 acquisition, L1 and L2 play different roles. We suggest that L2 German, which was shown to be the non-L3 language predominantly used to supply material for lexical construction attempts in the L3 (Williams \& Hammarberg, 1994), is activated in parallel to the L3 interlanguage, underlying L3 production and even L1 production. We refer to this as the DEFAULT SUPPLIER role. L1 English, on the other hand, is more seldom used in lexical construction attempts in the L3 or activated in parallel but rather is kept separate from the L3 and used largely with a metalinguistic function. We refer to this as the INSTRUMENTAL role. We propose a developmental model of L3 production based on de Bot's (1992) model of bilingual speech production but involving role assignment to the background languages, such that only the language which has been assigned the role of DEFAULT SUPPLIER is regularly activated in parallel to the L3 interlanguage. Over time, these two roles are largely taken over by the L3 itself. We suggest that these roles also exist in L2 acquisition but since there is only one background language, this takes over both roles and overt distinctions between them collapse.

\section{$1 \quad$ Introduction}


In the majority of studies of crosslinguistic influence in L2 acquisition, usually only the L1 is taken into account. In the case of a bilingual or polyglot, this may well be an oversimplification of the situation. A previously learned language (referred to here as an L2) may also have an influence on a learner's production in a new target language (referred to here as L3). The aim of this paper is to explore similarities and differences in the occurrence of L1 English and L2 German in what we refer to as non-adapted language switches using a case study of the first two years of L3 production in an adult learner of L3 whose background languages are L1 English and L2 German, and propose a developmental model of L3 production.

The influence of previously learned languages on a learner's production in the target language may show itself not only in the form of crosslinguistic influence on the learner's interlanguage (IL) but also in the non-target-language-adapted (non-TLadapted) occurrence of non-L3 languages during target language production. Intentional language switching is referred to in the bilingualism literature in terms of code-switching, borrowing, language mixing etc. In the L2 literature such language switching is referred to largely in terms of communication strategies (Bialystok, 1983; Færch \& Kasper, 1983) used by the learner to overcome problems arising from a limited lexicon. More recently, attention has also been drawn to non-intentional language switching (Poulisse \& Bongaerts, 1994), although this has also been documented elsewhere earlier (eg Vildomec, 1963). Non-intentional blending of languages has also been explored by the Kassel group in terms of competing plans (see eg Dechert $(1984,1989)$.

Research on non-adapted language switches in L2 acquisition shows that these can be due to various factors and thus have various functions, namely:

i) sociopsychologically motivated 
ii) proficiency-related (communication strategy, lack of TL knowledge; thematic continuity)

iii) metalinguistic comments (communication strategy, thematic discontinuity)

As regards sociopsychological factors, given that L2 learners are acquiring not only the language but also skills in how to use the language, it is likely that they are at the same time developing code-switching strategies. In the literature on bilingualism, these are generally regarded as being intentional and governed by sociopsychological factors pertaining to the content of the message and the interaction situation. Code-switching may involve varying stretches of discourse from single words up to complete turns (Færch \& Kasper, 1983). This decision itself often contains information about speaker attitude and communicative situation. If an L1 item is adjusted to IL phonology and/or morphology, however, this no longer constitutes code-switching, but is referred to as interlingual transfer (ibid, p.47).

There is also the case of proficiency-related language switches, which occur particularly in L2 beginners and intermediate learners, as opposed to more advanced L2 speakers, with the function bridging the communication gap in those cases where the learner's knowledge of the L2 is not sufficient. Tarone et al. (1983) place them within a subgroup of communication strategies which they refer to as avoidance strategies. Avoidance strategies are defined as a "means of getting around target language rules or forms which are not yet an established part of the learner's competence" (ibid, p.10).

As regards metalinguistic comment, in addition to the direct use of language switching in terms of incorporating an L1 element into the L2 target utterance, language switching may also be involved in metalinguistic communication, where the thematic continuity is broken in the sense that the communication situation itself is commented on. Færch \& Kasper (1983) point out that conversations between learners and native 
speakers often contain a fair amount of metalinguistic communication and that problems in interaction can be solved by the learner's signalling the problem to his interlocutor in an attempt to get the problem solved on a cooperative basis. This kind of appeal has been referred to as "self-initiated other-repairs" (Schegloff, Jefferson \& Sacks, 1977).

In addition to these three kinds of non-adapted switches, a fourth has been identified, referred to as "non-intentional language switches" (Poulisse \& Bongaerts, 1994), performance switches (Giesbers, 1989, from Poulisse \& Bongaerts, 1994), "slips of the tongue", "accidental L1 substitutions" (Poulisse, forthcoming), "automatic codeswitching" (Vogel, 1992) (cf. also Vildomec, 1963; Stedje, 1977; Ringbom, 1985).

Poulisse \& Bongaerts (1994), in a study of non-intentional language switches, operationalize the distinction in terms of hesitation phenomena and intonation. In this study, they analysed data from three groups of Dutch learners of English at three different proficiency levels: 15 second year university students of English (age 19-22), 15 grade 11 pupils (age 15-16) and 15 grade 9 pupils (age 13-14). The corpus consisted of ca 35 hours of speech (ca 140.000 words) and comprised data from a story retelling task, conversations with a native speaker of English, and two other tasks which required the speakers to refer to pictures of concrete objects and abstract shapes. English conversation or picture story retelling with a native speaker of English. It was found that the number of non-intentional language switches from the L1 were higher in the youngest group of pupils (who had had the least exposure to the L2) and lowest in the group of university students, who had had the most exposure. In addition, they found that, except for the group containing the subjects with the longest exposure to L2, function words were much more often involved in non-intentional non-adapted language switches than were content words 1 , which exceeded the ratio of function:content words in their corpus. 
Of 749 cases of the non-intentional language switches, 316 related to function words and 302 related to editing terms which Poulisse \& Bongaerts defined as being used by the speaker to comment on an error he had made or an inappropriate word he had used, and/or to warn the listener that what followed should be interpreted as a repair of what preceded (i.e. metalinguistic communication). The remaining 131 of the total 749 related to content words. This supports data from Giesbers (1989, from Poulisse \& Bongaerts) showing that such switches tend to involve function words, and also from Pfaff (1979), who found that L1 switches in an L2 sentence tend to consist of function words, sentence adverbials, tags and interjections. Further findings from Poulisse \& Bongaerts's data were that more content words were repaired than function words (53.4\% versus $30.7 \%$ respectively), and content words tended to be repaired before completion more so than function words (68.6\% versus $15.5 \%$, respectively). TLadapted language switches, on the other hand, in which the switched element is phonologically or morphologically adapted to the L2, involved very few function words, and appeared to be proficiency-related.

In short, there seem to be different kinds of language switches in L2 production which in turn may indicate that the L1 is being put to different uses. If this is so, what happens in the case of L3 acquisition, where the learner has not only the L1 but also one or several L2s which might be used? Is it only L1 that occurs in language switching, or does the L2 occur here too? If so, is L2 influence similar to L1 influence in terms of function and frequency?

\section{$2 \quad$ Bilingual language processing models}

In this section, we will present de Bot's (1992) model of bilingual speech production, together with Poulisse \& Bongaerts' (1994) critique and amendments to it, and discuss certain points which we regard as relevant for a developmental account of L3 
production. (See Poulisse, forthcoming, for a review of these and other bilingual processing models).

De Bot's model is based on Levelt's (1989) Speaking model, which is a model of speech in a monolingual situation. Levelt's model consists of four main components: a knowledge component, containing knowledge of the world and the interactional situation, a conceptualizer, in which preverbal messages are planned, a formulator, which converts the preverbal message into a speech plan by selecting the right words or lexical units and applying grammatical and phonological rules, and an articulator, which converts the speech plan into actual speech. De Bot's aim is to apply the model to language processing in bilinguals but change as little as possible of the original model, since this is well-founded on empirical evidence.

De Bot contends that a bilingual version of Levelt's model should be able to account for several things: firstly, the fact that two language systems can be used separately or mixed; secondly, the existence of cross-linguistic influence; thirdly, the effects of different levels of proficiency, and lastly, the ability to cope with a potentially unlimited number of languages. A central question formulated by de Bot is which part of the system in Levelt's model is involved in choosing the language to be used in an utterance, and what information this choice is based on. He accepts that there is awareness of cultural differences in interaction at the level of the knowledge component, and that the latter may thus contain a "discourse model", i.e. a list of limiting conditions for the speech which is to be generated. Since there are differences in concepts between languages, preverbal messages for the same speech intention for two languages may be different. Dismissing the idea that the preverbal message should contain all the possible relevant information for all possible languages for reasons of economy, de Bot assumes instead that it is in the first phase of processing in the conceptualizer, the macroplanning, that "the language to be used is selected on the basis of information from the discourse model, and that accordingly language-specific 
encoding takes place in microplanning" (de Bot 1992: 8), i.e. the second phase of the conceptualizer's processing.

Here, de Bot incorporates Green's (1986) suggestion that the different languages in a polyglot can have three levels of activation: selected (controls the speech output), active (plays a role in ongoing processing, runs parallel to the selected language, but is not articulated) or dormant (not active during ongoing processing), and stresses an important aspect of Green's proposal, namely that "the active language does everything the selected language also does: it selects lexical items, forms sentences, generates surface structures and eventually even makes a phonetic plan. The only difference is that the phonetic plan of the active language is not fed into the articulator" (de Bot 1992: 13). De Bot points out that the notion of parallel production is supported by findings from unilingual research into ambiguous words and speech errors. In summary, then, de Bot's bilingual model is such that the knowledge component sends information affecting language choice to the conceptualizer, which then selects one of the two languages. Both languages are then formulated in parallel but only the selected language is finally articulated.

Poulisse \& Bongaerts' (1994) criticism of de Bot's model is twofold. Firstly, it is not clear how two alternative speech plans can be formulated in parallel if the information in the preverbal message raises the activation level of one of the languages only, and secondly, it is uneconomical to have speech plans being formulated in parallel, since in theory there need not be any limit to the number of alternative plans that are being produced. Following de Groot (1992), they suggest instead that lexical items belonging to different languages are related to common conceptual nodes, so that translation equivalents and semantically related words share all or a number of meaning elements, both within and between languages. They suggest further that the information concerning language choice is added to the preverbal message in the form of a language component which plays a role in the activation of individual lexical items: "Thus, besides conceptual information activating particular lemmas, there will be an 
additional language component which spreads activation to the lemmas of that particular language. This implies that language is one of the features used for selection purposes, and hence that lemmas are tagged with a label which specifies to which language they belong..." (p. 41).

In Poulisse \& Bongaerts' model, then, the language tag provides the extra activation necessary to select a lemma from one language and prevent the other from being activated; in de Bot's model, lemmas from both languages are activated in parallel but only one of them is selected for articulation. Both models employ the same kind of mechanism, but involve suppression of competing elements at different levels. Poulisse $\&$ Bongaerts find their model more economical because the suppression of competing elements at an earlier stage in the model saves the extra processing load of double or multiple retrieval of lexemes and morphosyntactic information at lower levels in the model. Poulisse \& Bongaerts support their model with reference to studies on word translation, semantic priming and slips of the tongue in L2 production and suggest that their model can account for the kind of non-intentional switches they found in their data.

Four factors are mentioned in order to account for findings that function words are more involved in unintentional language switches (or performance switches, as Giesbers refers to them) than content words, namely frequency, recency, attention and word length. Giesbers (1989, from Poulisse \& Bongaerts) suggests that a contributory factor may be because L1 function words tend to be frequent. Poulisse \& Bongaerts agree with Giesbers, and find this the most plausible explanation, pointing out that within a framework of spreading activation, high-frequency words and words that have been used very recently require less activation for lexical access than low-frequency words and non-recent words. However, this doesn't really explain why function words are more frequent in switches anyway; although function words in L1 will at least initially be more frequent than function words in L2, also content words in L1 will be more frequent than content words in L2. Also, as Wode et al. (1992) point out, closed- 
class items are acquired fairly quickly by L2 learners, these constituting ca $30 \%$ or more of vocabulary items in the first month of L2 acquisition (Burmeister, 1986, from Wode et al., 1992). Bearing this in mind, it is more likely that the explanation for the frequency of function words in performance lies elsewhere, and is related to a qualitative difference in these categories.

Poulisse \& Bongaerts also discuss Giesbers' suggestion that function words may be more involved in language switches than content words because they carry less information and beginning learners who may because of limited attention need to make a choice between items they are going to attend to, may opt for the more meaningful content words, leaving the function words to look after themselves. Also, function words tend to be shorter than content words. This implies that they take less time to encode and articulate, which brings with it a lower probability that they will be intercepted before or during production. As a result, "more slips will be made in the selection of function words and fewer slips involving function words will be discovered by the monitor and intercepted" (p. 47).

A problematic area in Poulisse \& Bongaerts' discussion however is their claim to be able to explain Giesbers' performance switches as the erroneous access of an L1 item instead of an L2 item, and suggest that such switches are very similar to lexical substitution errors involving semantically-related lexical items within one language. Giesbers posits that intentional switches take place in the conceptual module and nonintentional ones in the morphophonological module, as a result of errors in the specification of the intended lexeme. However, merely postulating that non-intentional switching into L1 during L2 speech is the result of erroneous access of an L1 item instead of an L2 is a description, not an explanation, and does not in itself necessitate their own particular model. Where do these errors come from? Poulisse \& Bongaerts suggest that "unintended switches to the L1 are, in fact, very similar to lexical substitution errors involving semantically-related lexical items like low and high and fingers and toes" (1994:42). This however is problematic, as lexical substitution errors 
tend to involve mostly content words (Garman, 1990) and unintended switches to the L1 involve mostly function words.

\section{$3 \quad$ L3 acquisition research}

At this point we would like to compare the nature of non-intentional language switches in L2 acquisition with the nature of non-intentional language switches in L3 acquisition. In accordance with the literature, we use the term L3 to refer to the language that the learner is currently acquiring (corresponding to the language under study), L1 to refer to the learner's native language, and L2 to refer to any other previously learned non-native languages ${ }^{2}$.

In recent surveys of second language acquisition research, the phenomenon of other known languages playing a role in the acquisition of a subsequent language is sometimes briefly mentioned, such as in Sharwood Smith's (1994:198) definition of crosslinguistic influence as including "the influence of any other tongue known to the learner of that target language" (cf. also Kellerman, 1983:113; Odlin, 1989:27; Ellis, 1994:11 \& 339). There are a number of studies which are concerned with the question of whether bilinguals have an advantage over monolinguals in learning a subsequent language (see Klein, 1995 for a short overview), but to date there still exist only relatively few studies of L3 acquisition in which the role of non-native languages is investigated. However, those which have been carried out show clear evidence of L2 influence, at various levels (eg Chandrasekhar, 1965, 1978; Stedje, 1977; Ringbom, 1983, 1987; Hammarberg \& Hammarberg, 1993; Hammarberg \& Williams, 1993; Hufeisen, 1993; Vogel, 1992; Williams \& Hammarberg, 1994).

The majority of the studies mentioned above however tend to focus on identifiable L2 influence in the learner's IL, with little mention of unintentional switches. The few studies of L3 acquisition which do however mention unintentional language switches 
(Vildomec, 1963; Ringbom, 1983, 1987; Stedje, 1977) indicate that, as in the case of L2 acquisition, it is predominantly function words that are involved. The interesting point here is that the majority of unintentional language switches seem to involve L2, and not L1.

Vildomec's (1963) work is based on observations from a large number of subjects, although there is no detailed empirical data. He observes that in early L3 production, functors such as prepositions, articles and conjunctions tend to come from the L2, not from the L1, He states that "the tendency to transfer into an Le (i.e. an L2 in our terminology) short empty words from other Le's is especially strong. This transfer may occur even if the correct and incorrect words (and the material of the two languages as wholes) are rather dissimilar in sound" (ibid, p.170).

Ringbom's (1987) data are taken from ca. 11.000 English (L3) essays written by candidates from Finnish-language schools in the national matriculation examination in English, who had Swedish as an L2. In his corpus of lexical errors which he lists in an appendix, there are 187 instances of language switch (referred to by Ringbom as "complete language shift") from Swedish L2, and only 8 instances of language switching from Finnish L1. Of these 187 instances, 125 (67\%) can be identified as content words and $62(33 \%)$ as function words. ${ }^{3}$ Ringbom found that the words which were the most frequent were the clause connectors fast (= 'although', 13 instances), men (= 'but', 10 instances) and och (= 'and', 8 instances). He suggests that the existence of the English forms fast and men, although entirely different in meaning, may have influenced the writers, and also suggests lack of attention to form as a reason for why these items may be the most frequent automatic items: "it may well be that such links between major elements get less close attention than the actual form into which the writer wants to put his main ideas. This would probably be even more so in spoken language" (p. 122). ${ }^{4}$ Ringbom notes that another frequently recurring type of language switch (22 instances) involves words of foreign origin (e.g. auktoritet, intressant). 
Stedje's (1977) data comprises 55 five-minute recordings of Finnish learners of L3 German who had learnt L2 Swedish in Finland, and had spent not more than four years in Sweden. Her data showed a large (in the paper unspecified) number of instances of language switch, which appear to be non-intentional, as often the spontaneously produced Swedish word would be immediately corrected by the speaker (e.g. viele små, kleine Katzen). Stedje notes that it is often Swedish function words which occur (e.g. men, som, helt, för). She found no such instances of language switches from Finnish L1. Stedje suggests that one possible factor in such occurrences may be that Swedish is more closely related to German than is Finnish, which belongs to a different language family. However, in this connection, it is worth noting that she also found those non-intentional language switches which came from Swedish to be far more frequent in the Finnish students with L2 Swedish than in the Swedish students with L1 Swedish. In the latter group of learners, it was predominantly L2 English function words which occurred in language switches (Stedje, personal communication 5 ).

This is supported by anecdotal evidence from other L3 learners, including a case of Finnish L1, Swedish L2 and Estonian L3 (Päivi Juvonen, personal communication6). Estonian and Finnish are closely related to each other, whereas Swedish comes from a different language family. In the case of this subject, it would actually have been more successful to have used Finnish, both structurally and phonologically. Despite this, interference came primarily from L2 Swedish, and not L1 Finnish. This, although anecdotal, provides support for the notion that the L1/L2 status of a polyglot's other languages (i.e. whether the language is L1 or L2) may be at least as important as typological similarity in the occurrence of such switches.

If we compare these findings to findings concerning non-intentional language switches in L2 acquisition, we can see that in both L2 and L3 acquisition, non-intentional language switches consist mainly of function words. The interesting point as regards L3 acquisition is that these non-intentional switches appear to come predominantly 
from the L2, not from the L1. While it is possible that in the particular L3 cases documented, it is the similarity of the L2 to the L3 that is the major factor in automatic occurrences, Stedje's observation that in the learning of German, non-intentional Swedish switches occurred far more frequently in the case of L2 Swedish than in in the case of L1 Swedish would indicate that the occurrence of L2 may have to do with not just language typology but also the L1/L2 status of the languages involved.

This means that we have to look more carefully at arguments based on considerations of frequency, as put forward by Poulisse \& Bongaerts. Overall, it is likely that the L1 has been used at least as frequently as the L2, so if overall frequency were the determining factor, we would therefore expect L1 function words to occur in performance slips. If, on the other hand, typology were the main factor, then in Juvonen's case, Finnish rather than Swedish would have been activated, and, in Stedje's study, L1 Swedish would presumably have occurred as much as L2 Swedish in the acquisition of L3 German. However, from the evidence presented above, this is apparently not the case; it is predominantly L2 words which occur.

\section{$4 \quad$ Differing roles of $L 1$ and L2 in L3 acquisition}

We posit that L1 and L2 may play essentially different roles in L3 acquisition. In the case of L3 acquisition, the assignment of functional status of the various languages during online production simply in terms of selected, activated and dormant (Green, 1986; de Bot, 1992) may be an oversimplification which distorts the picture. If there is interference from both L1 and L2 in L3 production, but this interference is qualitatively different, rather than being distributed evenly over both languages, then we would have to assume that L1 and L2 are both active but in different ways. This is supported by two previous studies we carried out. 
A pilot study of L3 word construction attempts in an adult learner of L3 Swedish, with L1 English and L2 German as background languages in L3 Swedish (Williams \& Hammarberg, 1994) showed that L2 German is the language predominantly used to supply material for word construction attempts. Here, we found interference from L2 German not only as regards stems but also as regards bound morphemes. As regards English, we found no interference with bound morphemes and only few instances of interference with stems. In this study we referred to the function of a language supplying material for word construction attempts as a supplier function, and the language or languages that have this function as supplier languages. Since Swedish itself can act as a supplier language, we further made a distinction between intralingual supplier language (i.e. when Swedish was used in L3 Swedish wordconstruction attempts) and interlingual supplier language (i.e. when another language was used in L3 Swedish word-construction attempts). Here, L2 German was the main interlingual supplier language. We referred to this role as default interlingual supplier. In what follows we will simply refer to it as default supplier. In the same study, we observed that L1 English was seldom used in supplier role, but rather was used as a tool to facilitate communication in the form of metalinguistic comments, asides, requests for help etc. We referred to this latter role as instrumental. German did not occur at all in this role.

In the early stages of L3 acquisition in the same subject, the influence of L2 German was not limited to the morphological and lexical level but was strikingly apparent also at the phonological level (Hammarberg \& Hammarberg, 1993). In spontaneous speech, the subject's accent was initially strongly German, in terms of phonetic settings, prosody and voice quality. However, when asked to imitate L3 segments read by a native speaker, L2 influence disappeared and L1 English accent occurred. A further observation was that the strong L2 German phonological influence present in the early stages of the subject's L3 acquisition became less and less noticeable, so that after a period of one year, a gradual shift had taken place from a German to an English accent. When Swedish speakers listened to two recordings, one early recording and one 
recording a year later and were asked to identify the native language of the speaker, there was general agreement that the first version was spoken by a native speaker of German while majority choice for the second version was that it was was spoken by a native speaker of English.

It is the main purpose of the present study to examine more closely the roles played by L1 and L2 in L3 acquisition by looking at the distribution of L1 and L2 over the various kinds of functions involved in non-adapted language switches. The aims of the study, then are to see i) to what extent L1 and L2 occur in the various types of language switches identified above, ii) whether the roles of L1 and L2 change over time and iii) what theoretical consequences these findings may have for polyglot and bilingual speech processing models.

\section{$5 \quad$ Data}

\subsection{Subject and method}

The data presented here are taken from the project "Processes in Third Language Acquisition" a longitudinal case study of an adult learner of L3 Swedish (Sarah Williams, henceforth SW). It will be noted that the subject is the same as the first coauthor of this paper7. The material comprises recordings in the form of picture stories and conversations (with Björn Hammarberg, henceforth $\mathrm{BH}$ ) which were carried out at approximately two week intervals during the learner's first two years in Sweden (see Hammarberg \& Williams, 1993 for details). The data base comprises ca. 37.000 word tokens produced by the learner, and the working corpus for this study comprises 844 instances of non-adapted language switches.

SW's native language is British English and her L2s are German (fluent, near-native), French (advanced, non-fluent) and Italian (elementary, non-fluent). She studied French 
and German at university in England, spent one year in France during her university studies, and took an intensive one-month course in Italian at a language school in Florence at the age of 20. After finishing university, she lived in Germany for six years and came to Sweden direct from the period spent in Germany. Recordings began immediately after SW's arrival in Sweden. At the beginning of the recordings, the learner was 28 years of age. During the period of the recording (i.e. the first two years of her stay in Sweden) SW was working as a lecturer at the English Department at Stockholm University, a predominantly English-speaking environment. During this time she spent several weeks in both Germany and England, and received both German and English visitors at home in Sweden. Apart from this continued contact with German and English, her language environment was Swedish, which she acquired from her arrival on through regular everyday interactions with Swedes.

Since the recordings were all carried out in interaction with $\mathrm{BH}, \mathrm{BH}^{\prime}$ s language background is also relevant. BH's native language is Swedish and his L2s are English, German and French. He uses both English and Swedish as working languages, as is normal for academics in Sweden, and studied German at university.

\subsection{Coding}

We identified 4 major types of non-adapted language switches, which we define here as being neither phonologically or morphologically adapted to the target language. The first we refer to as EDIT. This category contains terms which are used to introduce a self-repair (eg no, sorry) and also includes interactive feedback signals (eg yeah, what). The second is referred to as META, and comprises metalinguistic comments or questions. The third is referred to as INSERT, and comprises both attempts to elicit the L3 word from the interlocutor and also instances of codeswitching which appear to be used in much the same way as proficient bilinguals might codeswitch (i.e. sociopsychologically motivated codeswitching). All of these three categories we 
regarded as having pragmatic purpose. In addition to these, there was a fourth category which did not appear to have any identificable pragmatic purpose. We referred to this category as $\underline{\boldsymbol{W}}$ ithout $\underline{\boldsymbol{I}} \mathrm{dentified} \underline{\boldsymbol{P}}$ ragmatic $\underline{\boldsymbol{P}}$ urpose (shortened to WIPP). We believe that our WIPP category corresponds, at least in part, to what Poulisse \& Bongaerts (1994) refer to as "non-intentional language switches", although it will be noted that their category also includes our category EDIT. We prefer to use the term WIPP for three reasons: firstly, to avoid the inherent problems involved in attempting to use intentionality as a working criterion, secondly, to avoid the ensuing implication that our other three categories are "intentional", and thirdly, to distinguish this category from EDIT. These categories were subcoded as shown in Table 1.

\section{TABLE 1 ABOUT HERE}

In all the examples given below, the items exemplifying the category in question are rendered in bold italics.

\section{EDIT}

An item was coded as EDIT (1) if it was used as an editing term in a self-repair sequence, or used to facilitate interaction. Transcription conventions are given in Appendix 1.

\section{(1) EDIT}

Examples:

06B 0184: > <der mann / nee > mannen

GLOSS: <the man / no>/the-man

17K 0021: $\quad$ i ett engelskttal-+ / <no $>$-talastelande+

GLOSS: in an english-speak- / <no> / -speaking country

32C $0042 \mathrm{~S} \quad\{\langle$ right $\rangle\}$ här finns de en kvinna som städer

GLOSS: <right>/ here is a woman who is cleaning 


\section{META}

This group was divided into two subcategories. COMMENT (2) was used to indicate a comment on the communicative situation or on the L3 text itself.

\section{(2) META COMMENT}

Examples:

01K 0069: $\quad<$ I think it depends who I'm talking to>

06K 0177: <does that mean 'problem'?>

26B 0011: <now it's working> [referring to the tape recorder]

An item was coded as FRAME (3) if it constituted a frame for an explicit word eliciting attempt. Note that in the examples below, it is only the part of the utterance in heavy print italics which has been coded as FRAME. The rest of the utterance is coded as INSERT (see next section).

\section{(3) META FRAME}

Examples:

02K 0105: <\% whats 'to like'?>

04C 0172: < < <ow do you say `enjoy yourself’?>

10B 0036: <whats 'umschlag'?>

GLOSS: what's envelope?

\section{INSERT}

This group was divided into three subcategories. We regarded items as constituting EXPLICIT ELICIT attempts (4) if they were inserted into a frame, and as constituting IMPLICIT ELICIT attempts (5) if there was no frame but their intonation was marked (rising). If items occurred in the absence of either of these two conditions, they were coded as NON-ELICIT (6). Any items that were phonologically or morphologically adapted to the Swedish L3 were excluded. Examples of these are given below. Note that in Group 4, it is only the part of the utterance in heavy print italics which has been 
coded as EXPLICIT ELICIT. The rest of the utterance is coded as FRAME (see previous section).

(4)

EXPLICIT ELICIT

Examples:

05K 0592: < <ho- how do you say 'they sound like'?>

14K 0021: <whats `to miss’?>

IMPLICIT ELICIT

Examples:

05K 0191: $\quad$ sen har \% har det här student \% / < looked at my watch'?>

GLOSS: then has \% has this student \% / <looked at my watch"?>

06B 0123: han skulle kunna kanske \% / < to throw'?>

GLOSS: he could perhaps \% / <'to throw'?〉

(6) NON-ELICIT

Examples:

06K 0210: ja hade m- månge <sachen>

GLOSS: I had m-many <things>

05K 0155: $\quad$ ja har sagt $\%$ till $\%$ till $<$ fahrer $>$ / till till mannen

GLOSS: I have said \% to \% to <driver> / to to the-man

We also coded for whether or not such items were morphologically adapted to the utterance by using English or German morphological rules, respectively (eg conjugated verbs, plural marking etc.). Since both L1 English and L2 German INSERT switches contained both morphologically adapted and morphologically non-adapted forms, (in terms of English and German morphology, respectively), as well as non-decidable cases, this did not prove to be of direct relevance for our main research question, 
which was to identify differences in the behaviour of L1 and L2. Consequently, these results will not be discussed further ${ }^{8}$.

\section{WIPP}

WIPP switches were those which, in contrast to the other three categories, were regarded as being $\boldsymbol{W}$ ithout $\boldsymbol{I}$ dentified $\boldsymbol{P r a g m a t i c} \boldsymbol{P}$ urpose. It was found to be typical of items in this category that there was immediate self-repair and/or abundant evidence from the preceding text that the corresponding items in the L3 were known to the subject.

\section{(7) WIPP}

Examples:

15K 0058: men alle personer <waren > \% va va mycke hjälpfull

GLOSS: but all the people <were> /\% were were very helpful

10B 0093: $\quad$ en tjuv \% <mit> / med en nyckel

GLOSS: a thief \% < with> / with a key

12B 0110: $\quad$ den $\langle\boldsymbol{k l e i}$ - $>$ / den den lite pojken

GLOSS: the <litt-> / the the little boy

A list of problematic areas within this categorization together with a discussion of how we dealt with them can be found in Appendix 2.

\section{$6 \quad$ Results}

In what follows we will use the term English corpus and German corpus to refer to the collection of English and German language switches respectively. The discussion will centre around the English and the German corpuses. Items from other L2s will be discussed in more detail later. Table 2 gives an overview of the functional distribution of the languages. 


\section{TABLE 2 ABOUT HERE}

It will be seen that both L1 and L2 non-adapted language switches occur in L3 production. In general, it will be seen that there are approximately three times as many switches involving L1 English as there are involving L2 German, i.e. 74\% of all switches involved English, and 24\% involve German. Items from other L2s are, on the whole, negligible, constituting only $2 \%$.

\section{$6.1 \quad E D I T$}

As regards the EDIT function, while more English is used than German, (70\% vs 29\%, respectively), this roughly reflects the general ratio of English and German occurrences 9 . Both languages occur here with roughly the same relation to their corpuses (9\% and 11\% respectively). There was only one instance of an EDIT term from another language.

\subsection{META}

As regards the META categories, both of the functions (COMMENT and FRAME) consisted entirely of English. Even in FRAMES in which German was used as the INSERT language, it was only English which comprised the FRAME.

\subsection{INSERT}

As regards the INSERT functions, the occurrence of L1 English and L2 German roughly reflected the general ratio of English and German occurrences (3:1). Within the subcategories EXPLICIT ELICIT, IMPLICIT ELICIT and NON-ELICIT, both English and German were used most in the NON-ELICIT category (i.e. "normal" 
codeswitching). In the ELICIT attempts, English occurred more in EXPLICIT ELICIT than IMPLICIT ELICIT, while the reverse was true of German. Indeed, as regards the EXPLICIT ELICIT category, 89\% of these were English and only $11 \%$ German. This however is in some ways not surprising, as the FRAME into which such attempts are slotted is always English; German in the EXPLICIT ELICIT position can be regarded as a case of double language switch. English EXPLICIT ELICIT constituted $21 \%$ of the English corpus, while German EXPLICIT ELICIT constituted only $8 \%$ of the German corpus.

Apart from the EXPLICIT ELICIT attempts, however, English and German readings for what percentage this constitutes of their respective corpuses are very similar: $12 \%$ and 12\% for IMPLICIT ELICIT attempts, and 30\% and 37\% for NON-ELICIT, i.e. "normal" codeswitching.

\subsection{WIPP}

As regards the last category, WIPP, 92\% of all WIPP switches were German, with only 4\% from English and 4\% from other L2s. Table 3 shows the distribution of function words and content words in WIPP switches. It will be seen that function words far outnumber the content words.

\section{TABLE 3 ABOUT HERE}

These results support previous findings from the literature that it is predominantly function words that occur in WIPP switches. In the case of L3 production, these function words are predominantly from the L2. As regards similarity in form, an asterisk beside an item indicates that this is not similar to the L3 form. Table 3a in Appendix 3 gives the Swedish equivalents of all WIPP items. It will be seen that not all of the types occurring as WIPP switches are similar in form to corresponding items in the L3 (cf. Vildomec, 1963); 40 out of 73 tokens are not directly similar in form. 
However, even when there is no similarity, if we look at the larger unit and context in the near vicinity, in the majority of cases there are lexical and/or structural features from German in the larger unit. Although this sometimes results in correct Swedish, this is not always the case. Some examples of these are given below.

Examples:

02K 0179 vi vi måste har en = / <wir müss-> / vir m- vir måste har \% fem fem minuter <vielleicht> \% \% German: Minuten

(NB: Swedish minuter here has German pronunication)

04C 0164 hon \% gör också = \% det vad <er> gör.

German: das was er macht

(NB: Correct Swedish: det han gör / det som <han> gör)

It will be noted that in some of these cases, although the English equivalent is also similar to the Swedish item in 12 cases (namely we must, what, how, we, there, could, ten, here, friday, little, typical, student), it is nevertheless the German that is used. This indicates that while formal similarity in the lexical item itself or in the structural context of that unit may play a role in WIPP switches, since it is by and large only L2 items that occur, any effect of similarity is consequently restricted to L2.

\subsection{Anomalous English}

An interesting observation we found was that the kind of English which occurred in the category INSERT was sometimes anomalous, although no cases of this were found when English was used in a META function. Of a total of 395 English INSERT items, we found 29 instances of anomalous English. These comprised 3 instances of slips of the tongue, 16 instances of what we refer to as German-based English, 8 instances of anomalous register/lexical usage, and 2 potential instances of transfer of training. 


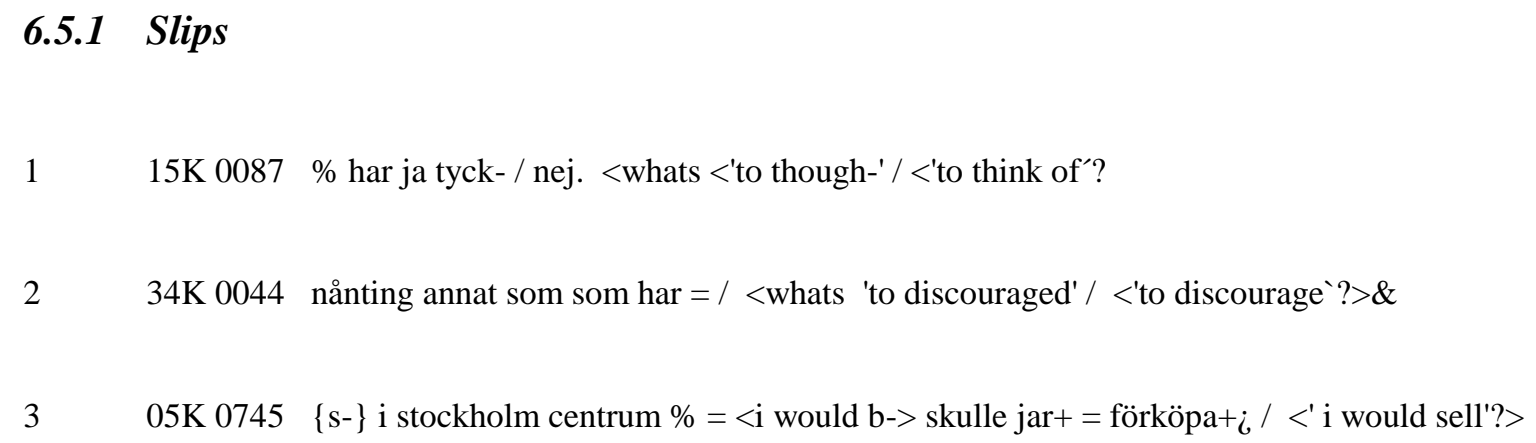

The three slips included two instances where the preterite form was combined with the infinitive form (Examples 1 and 2). In addition to these, there was one error in which a semantically related item buy was about to be used instead of the target item sell (Example 3). We did not consider these to be of further interest to our research question.

\subsubsection{German-based English}

Leaving aside the 3 slips mentioned above, in 16 of the 26 remaining instances of anomalous English, there seemed to be strong German influence. This occurred only in cases of INSERT, and not in cases where English was used in META function. In these 16 cases, English was not being used autonomously within its own language system, but rather was being used to render a literal translation of what the German would have been, if German had been uttered instead. German, then, seemed to be underlying the English. We refer to this as back-translation. All 16 cases of back-translation are presented below. ${ }^{10}$

$1 \quad 13 \mathrm{~K} 0392 \mathrm{~S}$ <how do you say 4a <'how father chr-'/ 'what father christmas looks like'?> 'hur santa claus ser ut'?

German: wie der Weihnachtsmann aussieht.

English: what Father Christmas looks like ${ }^{11}$ 
An overt example of this strategy in action, so to speak, is given in the example below:

$2 \quad 05 \mathrm{~K} 0665 \mathrm{~S}$

$<$ do do the swedes say <'f-' 'finde ich' or <'i i i find' or <'i i th- i think' in the sense of 'ich finde' or 'ich glaube'?>?

$3 \quad 04 \mathrm{~K} 0022$

() $\%$ ja finder $i=$ ja finder $i$ / <'i find'?>

The English back-translation (I find) of the German-based expression (ich finde) also occurs as complete, separate turntakes which actually adopt the pragmatic quality of what would have been in this case the German "Finde ich."

4
GLOSS: S: This Italian accent is like the Swedish accent.

B: Really?

S: At least, $I$ think so

B: Yes. That's interesting.

S: Yeah, I think so, because...

Other examples of German-based back-translation are given below:

5

02K 0194 <whats < 'when'? <'if'? 'if'?>

German: wenn

English: if

NB - German wenn can mean either when or if

$6 \quad 05 \mathrm{~K} 0243 \mathrm{~S}$ ja tror att ja har en en lite \% <interference of $>$ från sv

German: Interferenz von

English: interference from

NB - German von can mean either of or from

7 04K $0028 \mathrm{~S}<$ <'many things to do'.>

German: viele Sachen

English: a lot of things

NB This excerpt comprises part of a positive statement. Many tends to be used by native speakers of English mostly in questions or negative statements, rather than in positive statements, where $a$ lot of is preferred; German L2 speakers of English however tend to use many also in positive statements. 

German: mit denen ich gesprochen habe

English: who I've spoken to

04K $0161 \mathrm{~S}$ ja hade mycke $=\{$ mycke $\} / \&$

$$
\begin{aligned}
& \text { B }\{\text { 'tur'.\}\& } \\
& \text { S 'tur'.\& } \\
& \text { S '<luck>'?\& }
\end{aligned}
$$

German: ich hatte viel Glück

English: I was lucky

04K 0185 S \% ja ja kan \% \% <'this way' <'auf' / = <ho- how do you say <'in this way'? <'auf'> /

B \% 'så här'

S 'så här'. så här kan ja spara; spara mycket \% mycke timmar

German: auf diese Weise

English: this means I can... / like this / by doing this

05K $0357 \mathrm{~S}$ ja vilje \% ta- / \% säja \% '<i had to find' <or '<i i must find>'

German: ich mußte

English: I had to

05K $0444 \mathrm{~S}<\%$ how do i say <'i wouldn' t have thought so.'<or <'i wouldn't have imagined that.' German: das hätte ich mir nicht vorgestellt

English: I wouldn't have thought so

06B $0029 \mathrm{~S}$ <whats 'to \% = to say' <'tell' <'relate' <'she tells him about'?>

German: [jemandem etwas] sagen

English: to tell

$1406 \mathrm{~B} 0068 \mathrm{~S}$ och vet inte = vet inte vad han vad han $/\langle$ should $=$ think'? $\rangle$

German: was er denken soll

English: what to do / what he should do

09B $0211<$ 'he cant get away from the chair.'?>

German: er kann von dem Stuhl nicht weg; English: he can't get up from the chair

27B $0012 \mathrm{~S}$ de finns en = / ja. <whats <'a married pair'? <'married couple'?>

German: ein Ehepaar 
It will be noted that the above examples are typical of the kind of interlanguage utterances that native speakers of German make during L2 acquisition of English, i.e. the crosslinguistic effect of L1 German on L2 English is similar to the crosslinguistic effect of L2 German on L1 English during acquisition of L3 Swedish.

\subsubsection{Register / lexical item}

There were 8 cases of English in INSERT function where, instead of the target word, a related word was chosen, but one from the wrong register, or a less common alternative, as in the list of examples given below. This was found to extend even to structural choice. We interpreted such cases as being of the same nature as the German-based English mentioned above, except that here, instead of being a backtranslation of underlying German (i.e. German-based back-translation), the English seemed to be used to back-translate underlying interlanguage (IL) variants (IL-based back-translation), i.e. standard, unmarked, simplified forms. 
to have a drink

$522 \mathrm{~K} 0147$ inte ska = inte ska gör- göra $\langle$ babies $\rangle$.

so that they won't breed

have

for water to be

delivered

In all of the examples above, then, it would appear that the English is not used in a target-like fashion, but is moulded to fit in with the learner's interlanguage. In fact, it seems to be used to translate the exact form of the intended (but not yet produced) L3, or IL form. Here, one could posit that the form of the IL structure has already been decided upon, but cannot be executed in full because of lack of the required lexical item in the L3. Here, English is used to "render" the exact form sought after in the L3. English may be in the wrong register. This is the result of either simplification (cf. pidgin) or prototypicalization. In the case of the latter, perceived transferability may play a role. Kellerman (1983) posits that direct transfer from L1 is more likely from elements in the L1 which are perceived as having a high acceptability probability; colloquial expressions are often avoided as are more marked constructions such as accusative-infinitive construction. If this applies to direct transfer, then presumably it 
applies too to substituting the intended L3 item with the actual L1 item itself, as in the case of IL-based back-translation.

\subsubsection{Transfer of training}

A last minor point to be made in this section regards possible transfer of training. Here, we found only 2 examples, both of which are what SW believes to be the result of the kind of vocabulary training she received during German lessons at school. In both of these examples, the English produced corresponds to the English terms used in the German class at school in order to make clear certain semantic distinctions in German lexical items that are not overt in English. If this is the case, then it would indicate that the transfer of training which is one of the five factors named by Selinker (1972) in the creation of a learner's interlanguage may have hitherto unsuspected longterm effects not only on the L2 but also on the L1 and on subsequent strategies for language learning.

$1 \quad 04 \mathrm{~K} 0250 \mathrm{~B}$ do you want to pay them because they don't complain? or \% >

04K $0252 \mathrm{~S}<$ in order for them not to complain.>\&

English: so that they won't complain

Training: damit sie ... = in order for them

sodaß sie $\ldots=$ so that they (result)

$215 \mathrm{~K} 0026$ och \% ja ja känd- ja kände / <'i i got to know'?> 'ja k-

17K $0124 \%$ kan man känna / <how how do you say <'ken- kennenlernen' <'to get to know'?>\&

English: I met them / to meet

Training: treffen $=$ to meet by prior arrangement

kennenlernen $=$ to get to know

Although it might be objected that this kind of anomalous English may simply be a result of general L1 attrition in the subject, if this were the case, then we would expect 
similar phenomena to occur in the English used in the META category. No evidence of this was found. Also not surprisingly, we found no instances of German backtranslation (i.e. English-based German items).

What these findings show, then, is that even when L1 English appears to be being used as an INSERT language, it may still differ from L2 German, in the sense of being used instrumentally, to translate German-based or IL-based items. Although these occurrences comprise only ca $7 \%$ of the entire English INSERT corpus, the fact that they occurred at all shows that in these cases, English is being used in a special way. Also, as Ringbom (1987) points out, it is only when strategies result in non-target-like items that they are noticeable; in the rest of this section of the corpus, there may well be several other instances of this kind of L1 use which result however in target-like production of English, and are therefore impossible to identify.

\subsection{Summary of results}

\section{TABLE 4 ABOUT HERE}

Both L1 English and L2 German occur in the EDIT category and also in the INSERT category. In 16 cases, the English that occurred in the INSERT category appeared to be German-based back-translation, in 8 cases, the English here appeared to be IL-based back-translation, and there were 2 possible cases of influence from transfer from German language training. In the META category, it was exclusively L1 English that occurred. In the WIPP category, it was predominantly (92\%) L2 German that occurred. Here, function words (23 types, 52 tokens) outnumbered content words (12 types, 13 tokens). 37 of the German WIPP switches showed direct similarity to the Swedish form, as opposed to 28 which did not. However, of these 13 elements, a large proportion constituted part of a larger unit which was German-based (or where the Swedish construction and/or lexical items were similar to the German). 


\section{$7 \quad$ Longitudinal aspects}

Tables 5, 6 and 7 show the distribution of functions longitudinally over the corpus. In these tables, length of language exposure is shown in terms of years, months and weeks (i.e. 1;2.17 = 1 year, 2 months and 17 days). The date of SW's entry into Sweden was taken as Day 1.

\section{TABLES 5, 6 AND 7 ABOUT HERE}

The longitudinal data show a decline over time in the frequency of language switches. As regards L1 English language switches (see Table 5), a general decrease in their occurrence appears after approximately eight months. Within the category INSERT, although ELICIT switches begin to decrease from this point onwards, NON-ELICIT switches, which represent "normal" codeswitching, continue up until the end of the period studied. As regards German language switches (see Table 6), there is a marked decrease in their occurrence after roughly 4 months. This includes their occurrence in ELICIT function. They continue to occur sporadically in NON-ELICIT function (i.e. "normal" codeswitching) for the rest of the first year but then do not appear in this function from 1;3.0 onwards. There is also a decrease in WIPP switches, the last observed instance of this category occurring at 1;5.15. Language switches involving languages other than L1 English and L2 German (see Table 7) are relatively scarce and occur more or less only during the first two and a half months.

\section{Discussion}

\subsection{Role assignment}


The fact that only L1 English occurred in the META category and almost only L2 German in the WIPP category provides strong evidence that there is differentiated distribution of L1 English and L2 German in non-adapted language switches. The occurrence of English in META function provides extended evidence of findings from Williams \& Hammarberg (1994) that English is used for metalinguistic comments and asides, referred to as having INSTRUMENTAL role. It was found to be almost only German that supplied material for L3 lexical construction attempts (other than Swedish itself). We referred to German as having DEFAULT SUPPLIER role. In the present study, with only few exceptions, it is almost only German that occurs in WIPP function.

We posit that WIPP switches are symptomatic of German being the DEFAULT SUPPLIER language. This is supported by other data from the same subject showing German influence at various levels of language during the early stages of acquisition, not least at the level of structural and lexical planning. The notion that German, as DEFAULT SUPPLIER, is "online" all the time is supported by the apparent influence of German structure and lexical planning in some of the English INSERT utterances, where it is as if the English is being used for literal translations of underlying German. Indeed, the case of German-based back-translation would thus support the concept of German as DEFAULT SUPPLIER language and also English as INSTRUMENTAL language.

Where might the assignment of these roles come from? We suggest that the assignment of INSTRUMENTAL role may be based on the speaker's identification with a particular language, modified by a knowledge of which languages are known to the interlocutor, and also on the interlocutor's identification of the speaker with a particular language and cultural sphere. We suggest that the assignment of DEFAULT SUPPLIER role may be the result of interplay between four factors, namely, proficiency, typology, recency and L2 status. The language scoring the highest on all counts, so to speak, is the one which will be assigned default supplier role. 12 
Obviously, the effect of the various factors that determine the assignment of instrumental and default supplier role in each particular case will be subject to variation depending on the situation of the individual learner. It is a task for future research to explore this variation in detail. In the case under study here, English was used in everyday conversations between SW and BH during the early period of SW's residence in Sweden, a natural consequence of SW's English identity and the fact that both speakers knew English well. This would seem to motivate the use of English in the INSTRUMENTAL role in the Swedish conversations. Then, however, the question why German, and not English, assumes the DEFAULT SUPPLIER role, remains to be explained. If we consider the four factors mentioned above, we may summarize in the following schema how they apply to SW's case (cf. the facts given in section 5.1 above):
L1 English
L2 German
L2 French/Italian

PROFICIENCY $\quad+$

(Native level) (Near-native) (Lower than German)

TYPOLOGY

$+$

(Relatively close

$+$

to L3)

(Relatively close (Less close to L3)

to L3)

$\begin{array}{llll}\text { RECENCY } & + & + & - \\ & (\text { Still in regular } & \text { (Still in } & \text { (Not in current use) } \\ & \text { use }) & \text { occasional use }) & \\ & & & \\ \text { L2 STATUS } & - & + & +\end{array}$

This simplified schema points out some features that we think may be decisive in assigning the DEFAULT SUPPLIER role to German in SW's case, given the fact that 
both English and German (and less so, French) were available to both SW and $\mathrm{BH}$. Comparing L1 English and L2 German, we see that both obtain high scores (indicated here by pluses) for proficiency, typology and recency. SW could handle both languages with great ease. Both languages are relatively similar to Swedish. It could be argued that German is closer in vocabulary and means of word formation; on the other hand, this does not necessarily hold for lexical phrases or syntax. German scores high in recency, especially in view of the fact that SW moved directly to Sweden after several years' stay in Germany; English, too, was much used in and outside daily work. The decisive difference between English and German in this case appears to be in terms of L2 status. It seems to be this factor that crucially determines the default supplier role for German here, whereas English, despite high scores for the other factors, assumes a less prominent supplier role. But it is also clear that L2 status alone is not sufficient to motivate a default supplier role, as we can see when taking L2 French and Italian into account. These languages are outweighed by German in terms of proficiency, typological proximity to L3, and recency. Presumably, it is their L2 status which still allows them a minor role as supplier at the very early stage.

Although perceived typological similarity between L2 and L3 has been assumed to be the decisive factor in whether or not transfer takes place from L2 in L3 acquisition (Chandrasekhar, 1978; Ringbom, 1987; Vogel, 1992) and a consideration of proficiency and typology has been pointed out earlier as being of potential importance to the workings of a bilingual speech model (de Bot, 1992), what is new here is the incorporation of L1 versus L2 status itself into such a model. We believe that provided the factors of proficiency, typology and recency are at a sufficient level, L2s appear more likely to be activated than the L1 as supplier language during the early stages of L3 acquisition. Possible reasons for this include i) a different acquisition mechanism for L1 as opposed to L2 and hence, in L3 acquisition, a reactivation of the same acquisition mechanism as was in previous L2 acquisition, which in turn reactivates other L2s and ii) a desire to suppress L1 in the belief that this is inherently "nonforeign" and thus that using a non-L1 and hence "foreign" language would be a better 
strategy in acquiring another "foreign" language. This last factor is based on various introspective comments by SW that were documented during the early period of L3 acquisition, to the effect that she did not want to sound English (Hammarberg \& Williams, 1993). A pertinent question here is whether the fact that strong L2 German influence in the early stages of L3 acquisition, in terms of phonetic settings, prosody and voice quality gives way to English influence (Hammarberg \& Hammarberg, 1993), comes about as a result of activating the L2 or suppressing the L1, or both. This issue must however at present remain a matter for further speculation.

Once a language has been assigned DEFAULT SUPPLIER role, it becomes the main source of crosslinguistic influence. It is this language that is activated in parallel to the L3, and may also underlie the production of L3 (along with the developing L3 interlanguage). This L2 is the one used in the majority of interlingual lexical construction attempts up to the point at which proficiency in the L3 allows lexical construction attempts based predominantly on L3 itself and may also initially exert phonological/prosodic influence. It is because it is already parallel-activated that it acts as a default, such that i) it is this L2 that then surfaces in WIPP switches, which are possibly due to performance factors such as level of attention, concentration, fatigue, etc., and ii) it is this L2 that underlies and influences the online production of even other languages (notably even L1) when used in an L3 context. As proficiency increases in the L3, so too does the independence of L3; both INSTRUMENTAL role and SUPPLIER role are gradually taken over by the L3. In our study, this can be seen by looking at the longitudinal data, which show a decrease in German and English occurrences. This is also supported by data from Poulisse \& Bongaerts (1994) showing that non-intentional language switches (corresponding to our WIPP switches, which we posited as being symptomatic of DEFAULT SUPPLIER role) occur less frequently in more advanced learners than in beginners.

It will be noted that Poulisse \& Bongaerts' category "non-intentional language switches" covers both our WIPP category and also EDIT category. What distinguishes 
EDIT from WIPP is that EDIT consists of interactive pragmatic elements which are not integrated into the content and structure of of the ongoing utterance. As regards EDIT, again, both English and German are involved. Here, it is worth drawing attention to a neurological distinction in the processing of these two types of elements that has been found in crosslinguistic research on agrammatism in oral production (Menn \& Obler, 1990). Here, it has been shown that in agrammatism, there is a difference in the processing of content words, bound grammatical morphemes and free grammatical morphemes (functors). Content words tend to be preserved, bound grammatical morphemes are rarely omitted but can be substituted, and there is a high rate of omission in the majority of free grammatical morphemes. However, the kind of free grammatical morphemes which are discourse-controlled, such as fillers (eg "well" "y'know") and sentence-initial conjunctions (eg and, and then, and so etc.) were used abundantly. These latter correspond to the items found in our EDIT category. In other words, the free morphemes which could be regarded as resulting from the syntactic information present in a content-word lemma are those which are omitted in agrammatism, and occur in automatic switches from the L1 in L2 acquisition, and from the L2 in L3 acquisition (which could also be regarded as a kind of omission from the L3). On the other hand, the free morphemes which are discourse-controlled pragmatic elements, not dependent on syntactic integration, are those which are not affected in agrammatism and also those which, in switches, may occur from either L1 or L2. The existence of a different neurological mechanism in the processing of these two types of free morphemes may explain why WIPP may be symptomatic of DEFAULT SUPPLIER, containing as it does almost exclusively L2 German elements, whereas EDIT is not, since it contains both L1 English and L2 German elements.

\subsection{Relationship of our findings to models of bilingual speech production}

Poulisse \& Bongaerts' criticism of de Bot's (1992) model was twofold: firstly that if one language is selected already in the conceptualizer, then it is difficult to see how the 
other language could then be parallel-activated, and secondly, if this were somehow the case, it would, in the case of a polyglot, presumably lead to a potentially unlimited number of parallel-activated speech plans, which would be uneconomical. As regards the question of a shared or separate lexicon, Poulisse \& Bongaerts opt for a shared lexicon with language tags. The solution of having language tags for items in a shared lexicon however cannot by itself explain why in the case of L3 acquisition it seems to be basically only one language which occurs in WIPP switches. Individual language tags per item may serve to identify items belonging to one or the other language system, but having a DEFAULT SUPPLIER which is already more highly activated than other background languages would i) be able to explain our WIPP switches and ii) be more economical in the long run, in the sense of necessitating only one initial decision rather than several online decisions. Consequently, this means that (at least in addition to language tags), there must also be role assignment at a higher level.

Why should function words be more involved in WIPP switches than content words? Although any attempt to answer this question must at present be speculative, a possible explanation would be that function words are more automatized than content words. If the resources needed to block the articulation of a parallel-activated language are lowered, possibly due to factors such as tiredness, etc. (cf. Green, 1986), then presumably those elements which are more automatized, i.e. those over which the speaker has less control, will stand more chance of slipping through the block (cf. Ringbom, 1983).

At this point we would like to emphasize that at present, our model is a developmental one; the data presented here show that WIPP occurrences decrease over time. However, it has been observed (Stedje, personal communication ${ }^{13}$ ) that they may occur at a later period in situations of stress. SW's own informal observations of her later linguistic production support this. In addition, SW has observed that while such WIPP switches occur from L3 during L2 production when the speaker gets tired, they do not occur from L1 during L2 production, and only seldom from either L2 or L3 during L1 
production. Taken together, these observations suggest that the notion of role assignment in the form of DEFAULT SUPPLIER ${ }^{14}$ may also have relevance for a nondevelopmental steady-state model of language production in polyglots. In the case mentioned above, L3 Swedish thus appears to act as DEFAULT SUPPLIER for SW in her later use of L2 German. The latter observation given above also supports the notion that L1 is qualitatively different from a polyglot's other languages.

The assignment of DEFAULT SUPPLIER role has consequences for Levelt's and also Paradis' (1987) contention that there is no theoretical difference between the different registers used by a monolingual speaker and the languages spoken by a polyglot. Our findings would suggest that there is in fact a distinction, since it is unlikely that such roles would be assigned to registers.

The existence of the posited role assignment is also in line with other findings from studies on language acquisition, where it has been shown that language learners in the initial stages of acquisition adopt the strategy "one form, one function" (Andersen, 1984). Polyforms and polyfunctions appear at a later stage of acquisition, when the learner is more able to cope with such phenomena. In the context of L3 acquisition, there appear to be different roles which can be kept separate by being assigned to different languages. This is in line with the principle of simplicity outlined above. It is in the context of L3 acquisition that the distinction between such roles, and hence perhaps ultimately their identification and definition vis-à-vis each other, become visible. In the case of L3, then, we see that L1 and L2 have different roles, which we have called INSTRUMENTAL and SUPPLIER. In the case of L2 acquisition, these roles must both be assumed by the only candidate available, namely L1, and overt distinctions between them collapse. In other words, the distinctions that are apparent in L3 acquisition are no longer apparent in the case of L2 acquisition, since L1 takes on both SUPPLIER role and INSTRUMENTAL role. Conversely, this also implies that there is a qualitative difference between the acquisition of a first L2 and other L2s. 
A further point we would like to make here has to do with the problem of accounting for individual variation in language learning (eg Tarone, 1982, 1985; Ellis, 1985). Among the plethora of possible factors contributing to variability, very little attention has so far been given to the role of previously learned L2s. This picture is beginning to change, with studies comparing language learning in monolinguals and bilinguals (eg Mägiste, 1986; Klein, 1995). However, as pointed out earlier, such studies focus on issues pertaining to mental flexibility. The results of this study indicate that previously learnt L2s may play a role in individual variation in other ways. If it is predominantly an L2 and not the L1 that acts as a supplier language during the early stages of L3 acquisition, then simply looking to the learner's L1 (in conjunction of course with language universal factors etc.) will not give a full picture of the acquisition process (cf. Chandrasekhar, 1978). We would stress, then, that a consideration of previously learned L2s may go some way towards accounting for the individual variation in learners that has been widely documented in the L2 literature, and even in cases of L2 acquisition in which there are no previously learned L2s, a consideration of the extent to which L1 is used in supplier role and in instrumental role may contribute to a better understanding of individual variation.

In conclusion, we support the principle behind de Bot's (1992:2) statement that since every unilingual speaker has the potential to become bilingual, a basic model of speech production should be concerned with bilingualism, with an option to have a unilingual version. A related view is expressed by Cook (1992) who argues for the primacy of "multicompetence" over "monocompetence". Both de Bot and Cook refer to the knowledge of two or more languages as a normal state, but do this in passing, limiting their own discussion to a bilingual L1-L2 situation. However, in the light of our L3 data, we would expand this: since every unilingual speaker has the potential to become multilingual, a basic model of speech production should be concerned with multilingualism, with options to have both bilingual and monolingual versions. 


\section{NOTES}

* Sarah Williams died in December 1996 when this study was essentially completed. Her key role in our L3 project will be apparent in the paper, and the memory of a bright colleague and a good friend will stay alive. - I would like to thank Theo Bongaerts, Kees de Bot and Nanda Poulisse as well as three anonymous reviewers for giving us valuable comments on an earlier version of this paper. $-\mathrm{BH}$.

1 Note that the definition of what exactly constitutes content and function words is not resolved (cf. discussion in Muysken, 1995). However, where this is relevant to a discussion of our own data (Section 6.4), the reader will find a complete list of all the items we categorized in Table 3.

2 There are several qualitative differences between the acquisition of a first L2 and a subsequently acquired L2, which ultimately means that the learner comes to the L3 acquisition task better equipped than was the case with the very first L2, in various ways. These include awareness of linguistic diversity, previous experience of certain strategies in L2 acquisition, etc.

3 There are a handful of items, mainly adverbs, which are somewhat difficult to place. See Footnote 1. They are counted here as content words.

4 There may certainly be differences in the way language switching works in writing (as in the case of Ringbom's study) and in speech. We cannot, however, explore this point in the present context. As Ringbom points out, language switching is likely to be even more frequent in speech; thus, the passage we quoted from him goes on, "In fact, it is probable that language shifts occur much more frequently in spoken than in written language, but even in the present written corpus complete shifts of Swedish function words make up a fair proportion $(18 \%)$ of the total number of lexical errors due to Swedish influence." (Ringbom, 1987:122.)

5 Astrid Stedje, Department of German, Umeå University, Sweden. 
We would like to point out that work on this study commenced more than three years after the final recording was made. During the time of the recordings, SW had not carried out any research on second or third language acquisition. Although there was some metalinguistic discussion and SW recorded introspective diary entries, at no point during the period of the recordings was there any discussion as to what kind of analyses would eventually be carried out on the data. The transcriptions were carried out by a research assistant after the last of this material had been recorded. Thus, the present authors do not feel that the data were in any way influenced by this or other potential studies at the time of collection and transcription.

Such results might however have a bearing on a model of codeswitching such as that presented in Myers-Scotton (1993), which posits that all embedded language items are morphologically adapted to the matrix language, although since our results are developmental and Myers-Scotton explicitly states that her model is not (p.viii), this will not be discuss further here.

9 It should however be pointed out that the number of German EDIT terms would have been increased enormously if we had included the items "ja" and "also", which were abundant throughout the entire corpus. These were however not included as Swedish has two almost identical counterparts ( $j a$ and alltså) and it was not possible to ascertain what status these items had in our material, i.e. whether they belong to SW's interlanguage or whether they are indeed non-adapted language switches. However, regardless of whether these features themselves came from German or Swedish, the frequency of their ocurrence far exceeded that of native speakers of Swedish.

10 Some readers have suggested that some of these cases (nos. $7,8,12$ ) may not actually be so unnormal in English. They were interpreted in this way by SW, who insisted that she would not spontaneously use these forms in natural English discourse, and identified them as backtranslations from German. I leave them as they stand, with this clarification. - BH.

11 NB: The fact that Swedish has similar structure to German may mean that it is Swedish which is here being used as INTRALINGUAL SUPPLIER. However, this is unlikely in view of the fact that German appears to underlie the other examples in this category. 
12 This may provide an alternative explanation for Thomas' (1990) finding that Chinese/English bilinguals did not use their Chinese when learning Japanese; it may be not simply that English is their dominant language, as Thomas suggests, but rather that Chinese is their L1, and it is initially L2 that is activated during the early stages of L3 acquisition.

13 See Footnote 5.

14 In this paper the term DEFAULT SUPPLIER is used within a developmental framework. We recognise that the role of a parallel-activated language in a steady-state model may not necessarily fulfil the same functions as a parallel-activated language in a developmental model; we use the same term here however for the sake of simplicity, to denote the idea that even in a steady-state model, it may be the case that only one of a polyglot's other languages is parallel-activated. 


\section{REFERENCES}

Andersen, R.W. (1984). "The one to one principle in interlanguage construction". Language Learning, 34, 77-95.

Bialystok, E. (1983). "Some factors in the selection and implementation of communication strategies". In: C. Færch \& G. Kasper (eds), Strategies in interlanguage communication. London \& New York: Longman. 100-118.

Burmeister, P. (1986). Linguistische Untersuchung zum L2-Lexikonerwerb. Magister dissertation: Englisches Seminar, Kiel University.

Chandrasekhar, A. (1965). A new approach to language teaching. Delhi: Linguistic Circle of Delhi.

Chandrasekhar, A. (1978). "Base language". IRAL, 16, 62-65.

De Bot, K. (1992). "A bilingual production model: Levelt's "Speaking" model adapted". Applied Linguistics, 13/1, 1-24.

Dechert, H.W. (1984) "Second language production: six hypotheses". In: H.W.Dechert, D. Möhle \& M. Raupach (eds), Second Language Productions. Tübingen: Gunter Narr Verlag.

Dechert, H.W. (1989), "Competing plans in second language processing". In: H.W. Dechert (ed), Current Trends in European Second Language Acquisition Research. Clevedon \& Philadelphia: Multilingual Matters.

De Groot, A. (1992). "Bilingual lexical representation: a closer look at the conceptual representations". In: R. Frost \& L. Katz (eds), Orthography, Phonology, Morphology, and Meaning. Amsterdam: Elsevier.

Ellis, R. (1985). Understanding second language acquisition. Oxford: Oxford University Press.

Ellis, R. (1994). The study of second language acquisition. Oxford: Oxford University Press.

Færch, C. \& Kasper, G. (1983). "Plans and strategies in foreign language communication". In: C. Færch \& G. Kasper (eds), Strategies in interlanguage communication. London \& New York: Longman. 20-60.

Garman, M. (1990). Psycholinguistics. Cambridge: Cambridge University Press.

Giesbers, H. (1989). Code-switching tussen Dialect en Standaardtaal. Amsterdam: P.J. MeertensInstituut.

Green, D.W. (1986). "Control, activation and resource: a framework and a model for the control of speech in bilinguals". Brain and Language, 27, 210-23.

Hammarberg, B. (1993). Principer för transkription av talspråkstexter i ASU- och L3-projekten. Working paper, Department of Linguistics, Stockholm University.

Hammarberg, B. \& Hammarberg, B. (1993). "Articulatory re-setting in the acquisition of new languages". Reports from the Department of Phonetics, University of Umeå, PHONUM 2, 61-67. 
Hammarberg, B. \& Williams, S. (1993). "A study of third language acquisition". In: B. Hammarberg, (ed), Problem, Process, Product in Language Learning. Stockholm University, Dept. of Linguistics, 60-70.

Hammarberg, B. \& Williams, S. (in progress). Lexical construction attempts in L3.

Hufeisen, B. (1993). "Fehleranalyse: English als L2 und Deutsch als L3". IRAL, 31, 242-256.

Kellerman, E. (1983). "Now you see it, now you don`t". In: Gass, S. \& Selinker, L. (eds), Language transfer in language learning. Rowley, Mass.: Newbury House. 112-134.

Klein, E.C. (1995). "Second versus third language acquisition: is there a difference?". Language Learning, 45/3, 419-465.

Levelt, W.J.M. (1989). Speaking. From intention to articulation. Cambridge, Mass.: MIT Press.

Meara, P. (1994). Self-organization in bilingual lexicons. Manuscript.

Muysken, P. (1995). Code-switching and grammatical theory. In: L. Milroy \& Pl Muysken (eds), One speaker, two languages. Cross-disciplinary perspectives on code-switching. Cambridge: Cambridge University Press.

Myers-Scotton, C. (1993). Duelling languages. Grammatical structure in codeswitching. Oxford: Clarendon Press.

Mägiste, E. (1986). "Selected issues in second and third language learning". In: J. Vaid (ed): Language processing in bilinguals: psycholinguistic and neuropsychological perspectives. Hillsdale: Erlbaum. 97-122.

Odlin, T. (1989). Language transfer. Cambridge: Cambridge University Press.

Paradis, (1987). The assessment of bilingual aphasia. Hillsdale: Erlsbaum.

Pfaff, C. (1979). Constraints on language mixing: intrasentential code-switching and borrowing in Spanish/English. Language, 55, 291-318.

Poulisse, N. (forthcoming). "Language production in bilinguals". To appear in: A. de Groot \& J. Knoll (eds), Tutorials in Bilingualism: Psycholinguistic Perspectives. Hillsdale, N.J.: Lawrence Erlbaum.

Poulisse, N. \& Bongaerts, T. (1994). First language use in second language production. Applied Linguistics, 15/1, 36-57.

Ringbom, H. (1982). "The influence of other languages on the vocabulary of foreign language learners". In: G. Nickel \& D. Mehls (eds), Error Analysis, contrastive linguistics and second language learning. Papers from the 6th Congress of Applied Linguistics, Lund, 1981 (Special Issue). Iral, 85-96.

Ringbom, H. (1983). "Borrowing and lexical transfer". Applied Linguistics, 4/3, 207-212.

Ringbom, H.(1985). "The influence of the Swedish on the English of Finnish learners". Foreign Language Learning and Bilingualism. Publications of the Research Institute of the Åbo Akademi Foundation 105, 39-71. Åbo,: Åbo Akademi. 
Ringbom, H. (1987). The role of the first language in foreign language learning. Clevedon, Philadelphia: Multilingual Matters.

Schegloff, E.A., Jefferson, G. \& Sacks, H. (1977). The preference for self-correction in the organisation of self-repair in conversation. Language, 53, 361-382.

Selinker, L. (1972). "Interlanguage". IRAL, 10, 209-231.

Sharwood Smith, M. (1994). Second language learning. London and New York: Longman.

Stedje, A. (1977). Tredjespråksinterferens i fritt tal - en jämförande studie. In: R. Palmberg \& Håkan Ringbom (eds), Papers from the conference on contrastive linguistics and error analysis. Stockhom \& Åbo, 7-8 February, 1977. Åbo: Åbo Akademi.

Tarone, E. (1982). Systematicity and attention in interlanguage. Language Learning, 32, 69-82.

Tarone, E. (1985). Variability in interlanguage use: a study of style-shifting in morphology and syntax. Language Learning, 35, 373-404.

Tarone, E., Cohen, A.D. \& Dumas, G. (1983). "A closer look at some interlanguage terminology: a framework for communication strategies". In: C. Færch \& G. Kasper (eds), Strategies in interlanguage communication. London \& New York: Longman. 4-14.

Thomas, M. (1990). "Acquisition of the Japanese reflexive zibu by unilingual and multilingual learners". In: H. Burmeister \& P. Rounds (eds). Variability in second language acquisition: Proceedings of the Tenth Meeting of the Second Language Reseearch Forum. Eugene: University of Oregon.

Vildomec, V. (1963). Multilingualism. Netherlands: A.W. Sythoff-Leyden.

Vogel, T. (1992). "' English und Deutsch gibt es immer Krieg' . Sprachverarbeitungsprozesse beim Erwerb des Deutschen asl Drittsprache". Zielsprache Deutsch, 23/2, 95.99.

Williams, S. \& Hammarberg, B. (1994). An L3 learner's lexicon expansion attempts during interaction. Paper presented at EUROSLA, Aix-en-Provence, 1994.

Wode, H., Rohde, A., Gassen, F., Weiss, B., Jekat, M \& Jung, P. (1992). L1, L2 L3: continuity vs. discontinuity in lexical acquisition. In: P.J.L. Arnaud \& H. Béjoint (eds), Vocabulary and applied linguistics. London: MacMillan. 52-61. 


\section{APPENDICES}

\section{Appendix 1: Transcription Conventions}

Transcription conventions used are based on Hammarberg (1993). A modified form of standard Swedish orthography is used, in which the common 'spoken language forms' (such as $d e, v a$, mycke etc. for standard written det, var, mycket etc.) are rendered when the speaker uses them.

06B 0184: $\quad 06=$ Recording number 6,

$$
\mathrm{B} \text { or } \mathrm{C}=\text { picture story narration }
$$$$
0184=\text { line number }
$$

17K 0021: $\quad 17=$ Recording number 17

$\mathrm{K}=$ conversation

$0021=$ line number

$=\quad$ empty pause

$\%$ pause filler

$\mathrm{xxx} \quad$ unidentifiable item

- $\quad$ interrupted word

$+\quad$ morphologically unclear ending

/ interruption, reformulation

1 at the beginning of a turntake if this is a continuation of speaker's previous utterance

? completion of question macrosyntagm

. completed macrosyntagm excluding question macrosyntagms

$i \quad$ questioned expression (indication by intonation that feedback is required pertaining to this item)

' ' used when the speaker quotes an expression

$<\quad$ non-adapted non-L3 languages 


\section{Appendix 2: Problematic categorisation, from Section 5.3}

\section{Borrowings and loan words}

Borrowings and loan words occur particularly in cases in which the referent of the element in question exists in only one of the cultures in question. The question also arises as to whether pronunciation makes a difference; if an inserted element is pronounced with a Swedish accent, does this change its status? In the first example below, the items good friday and easter monday are very definitely English. These bank holidays also happen to exist in Sweden and have Swedish names (långfredag and annandag påsk), but this is cultural knowledge; many bank holidays are national only. Also, how should one classify items that presumably are international, such as champagne, which might well have been taken from the German although it also exists in both Swedish and English. And if SW believes that sekt is also an international concept, would this change its status as a quote?

Example: $\quad$ S:...i england har har man också <good friday> och <easter monday> GLOSS: in England we also have good friday and easter monday

Example: $\quad$ S....man dricker champagne eller $\langle$ sekt $\rangle$. GLOSS: they drink champagne or "sekt"

If a borrowed item, although acceptable in Swedish, is not generally an established item in normal Swedish, we included this in the INSERT category. On the other hand, loan words which have been incorporated into Swedish were not included in the corpus.

\section{Interlanguage or insert?}

It was sometimes difficult to see whether an L2 item was being used with INSERT function or in an attempt to construct a word in L3. In the example below, the German form gans comes second in a sequence of word-construction attempts, but is however very similar to the other forms. In cases of doubt these were not included in the corpus.

Example: dom äter inte... ge-... gens... gans... jans... jens...

GLOSS: they don't eat...goo-...goose...goose...goose...goose

Particularly during the first few months, there were 43 instances of items which on the one hand, may have come from other languages, but were being used with the wrong meaning (eg per, from Italian, used with the meaning "in"; $i$, from Italian, used as definite article plural; /e/, from either French or 
Italian, used with the meaning "and"). Since these seemed to constitute part of the subject's IL, they were not included in the corpus of language switches.

\section{Distinction between meta and insert/non-elicit}

Where a language switch occurred when the content of the L3 text actually included a meta comment, we assigned this to the category INSERT/NON-ELICIT, our criterion for assignment to the META category being that the item does not constitute part of the content of the text, but is distinct from it.

\section{Meta versus frame}

Cases such as the one below were classified as COMMENT rather than FRAME, as it was not an explicit eliciting attempt (cf. What is the word for "leg"?)

Example: $1<\mathrm{i}$ do- $\mathrm{i}$ dont know what the word for $\left\langle{ }^{\prime} \mathrm{leg}^{\prime}\right.$ is. $>$

\section{Meta versus edit}

The borderline between META and EDIT categories was occasionally difficult. We classified nonreferential comments such as oh god as EDIT and referential comments oh god that's difficult as META, although obviously the underlying meaning of both, when uttered as an expression of the speaker's difficult with the text, is the same. The distinction we made between META and EDIT, then, rested on whether the utterance contained a referring term (META) or not (EDIT).

\section{OK}

$\mathrm{OK}$ is an international term, and in our material it is often used pragmatically at the beginning of a turntake, to register acknowledgement of the interlocutor's contribution or acceptance of a turn. Although it is international, we have regarded it as an English item since when it occurs in our material, it is uttered with an English accent.

\section{Implicit elicit versus non-elicit}

In cases of potential left-dislocation, it was difficult to decide if an item was embedded in a FRAME, whether it constituted an IMPLICIT ELICIT attempt, or whether it constituted simply a NON-ELICIT insertion. In such cases, we classified the operative utterance as FRAME if it contained anaphoric reference (eg that in the example below).

Example: han \% bli \% han bli \% / <'excited' <'aufgeregt' < how do you you say that?> 
TABLE 3A IN HERE 
Table 1: Coding categories

\begin{tabular}{|l|l|l|l|}
\hline CATEGORY & \multicolumn{2}{|l|}{ DESCRIPTION } \\
\hline EDIT & $(1)$ & - & \\
\hline META & $(2)$ & COMMENT & \\
\hline & $(3)$ & FRAME & (containing EXPLICIT ELICIT) \\
\hline INSERT & $(4)$ & EXPLICIT ELICIT & (situated in FRAME) \\
\hline & $(5)$ & IMPLICIT ELICIT & (not situated in FRAME, but with rising intonation) \\
\hline & $(6)$ & NON-ELICIT & (no marked intonation) \\
\hline WIPP & $(7)$ & - & \\
\hline
\end{tabular}


Table 2: Overview of language switch distribution across categories for L1 English, L2 German, and other L2s.

\begin{tabular}{|c|c|c|c|c|c|c|c|c|c|c|c|c|c|c|}
\hline \multicolumn{2}{|c|}{ CATEGORY } & \multicolumn{4}{|c|}{ L1 ENGLISH } & \multicolumn{4}{|c|}{ L2 GERMAN } & \multicolumn{4}{|c|}{ OTHER L2s } & \multirow[b]{2}{*}{$\begin{array}{l}\text { total } \\
\text { (f) }\end{array}$} \\
\hline & & $\begin{array}{l}\mathrm{E} \\
(\mathrm{f})\end{array}$ & $\begin{array}{l}\mathrm{E} \% \\
\text { all }\end{array}$ & $\begin{array}{l}\mathrm{E} \% \\
\mathrm{E}\end{array}$ & $\begin{array}{l}\mathrm{E} \% \\
\text { cat }\end{array}$ & $\begin{array}{l}\text { G } \\
\text { (f) }\end{array}$ & $\begin{array}{l}\mathrm{G} \% \\
\text { all }\end{array}$ & $\begin{array}{l}\text { G\% } \\
\mathrm{G}\end{array}$ & $\begin{array}{l}\mathrm{G} \% \\
\text { cat }\end{array}$ & \begin{tabular}{|l}
$\mathrm{O}$ \\
(f) \\
\end{tabular} & $\begin{array}{l}\mathrm{O} \% \\
\text { all }\end{array}$ & $\begin{array}{l}\mathrm{O} \% \\
\mathrm{O}\end{array}$ & $\begin{array}{l}\mathrm{O} \% \\
\text { cat }\end{array}$ & \\
\hline (1) & EDIT & 57 & 7 & 9 & 70 & 24 & 3 & 11 & 29 & 1 & - & 6 & 1 & 82 \\
\hline & & & & & & & & & & & & & & \\
\hline (2) & META COMMENT & 73 & 9 & 12 & 100 & - & & & & - & & & & 73 \\
\hline (3) & META FRAME & 92 & 11 & 15 & 100 & - & & & & - & & & & 92 \\
\hline & META TOTAL & 165 & 19 & 26 & 100 & & & & & & & & & 165 \\
\hline (4) & INSERT ELIC EXPLICIT & 133 & 16 & 21 & 89 & 16 & 2 & 8 & 11 & 1 & & 6 & & 150 \\
\hline (5) & INSERT ELIC IMPLICIT & 75 & 9 & 12 & 73 & 25 & 3 & 12 & 24 & 3 & & 19 & 3 & 103 \\
\hline (6) & INSERT NON-ELICIT & 187 & 22 & 30 & 68 & 78 & 9 & 37 & 29 & 8 & 1 & 50 & 3 & 273 \\
\hline & INSERT TOTAL & 395 & 47 & 64 & 75 & 119 & 14 & 57 & 23 & 12 & 1 & 75 & 2 & 526 \\
\hline (7) & WIPP & 3 & & & 4 & 65 & 8 & 31 & 92 & 3 & & & 4 & 71 \\
\hline & & & & & & & & & & & & & & \\
\hline & TOTAL & 620 & 74 & & & 208 & 24 & & & 16 & 2 & & & 844 \\
\hline
\end{tabular}

KEY: (applies to German and Other L2 categories correspondingly)

$\mathrm{E}$ (f) shows the frequency.

$\mathrm{E} \%$ all shows the percentage this constitutes of the entire corpus of switches.

$\mathrm{E} \% \mathrm{E}$ shows the percentage this constitutes of the English corpus of switches.

E\% cat shows the percentage this constitutes of this particular category. 
Table 3: List of items in WIPP switches and their frequencies

\begin{tabular}{|c|c|c|c|c|}
\hline \multirow[t]{2}{*}{ LANGUAGE } & \multicolumn{2}{|c|}{ FUNCTION WORDS } & \multicolumn{2}{|c|}{ CONTENT WORDS } \\
\hline & TYPE & TOKEN & TYPE & TOKEN \\
\hline L1 ENGLISH & $\begin{array}{l}\text { even } \\
\text { the } \quad *\end{array}$ & $\begin{array}{l}2 \\
1 \\
\end{array}$ & & \\
\hline total & 2 & $3(* 1)$ & & \\
\hline L2 GERMAN & $\begin{array}{ll}\text { dann } & \\
\text { er } & * \\
\text { und } & * \\
\text { ein } & \\
\text { am } & * \\
\text { die } & \\
\text { mit } & \\
\text { so } & \\
\text { da } & \\
\text { der } & \\
\text { es } & * \\
\text { hier } & \\
\text { das } & * \\
\text { ihr } & * \\
\text { konn- } & \\
\text { ni-(cht) } & * \\
\text { ob } & \\
\text { waren } & \\
\text { was } & \\
\text { wer } & \\
\text { wie } & * \\
\text { wir } & \\
\text { wir müss- } & \end{array}$ & $\begin{array}{l}7 \\
7 \\
4 \\
4 \\
3 \\
3 \\
3 \\
3 \\
2 \\
2 \\
2 \\
2 \\
1 \\
1 \\
1 \\
1 \\
1 \\
1 \\
1 \\
1 \\
1 \\
1 \\
1\end{array}$ & $\begin{array}{ll}\text { klei- } & * \\
\text { be-(wertet) } & \\
\text { frei-(tag) } & \\
\text { ging } & \\
\text { gut } & * \\
\text { plötzlich } & \\
\text { studen- } & \\
\text { typ-(isch) } & \\
\text { vielleicht } & * \\
\text { wein } & \\
\text { wohnt- } & \\
\text { ze-(hn) } & *\end{array}$ & $\begin{array}{l}2 \\
1 \\
1 \\
1 \\
1 \\
1 \\
1 \\
1 \\
1 \\
1 \\
1 \\
1\end{array}$ \\
\hline total & 23 & $52(* 23)$ & 12 & $13(* 5)$ \\
\hline OTHER L2 & $\begin{array}{l}\text { un } \\
\text { comment }\end{array}$ & $\begin{array}{l}2 \\
1\end{array}$ & & \\
\hline total & 2 & $3(* 1)$ & 12 & 13 \\
\hline TOTAL & 27 & $62(* 25)$ & 12 & $13(* 5)$ \\
\hline
\end{tabular}

* beside an item indicates that this is not similar to the L3 form.

NB: For reasons of clarity, the non-uttered completions of some of the interrupted lexical items, as apparent from their original context, are given in parentheses. 
Table 4: Summary of results for L1 English and L2 German non-adapted language switches

\begin{tabular}{|l|r|r|}
\hline CATEGORY & L1 ENGLISH & L2 GERMAN \\
\hline EDIT & $70 \%$ & $29 \%$ \\
\hline META & $100 \%$ & $0 \%$ \\
\hline INSERT EXPLICIT ELICIT & $89 \%$ & $11 \%$ \\
\hline INSERT IMPLICIT ELICIT & $73 \%$ & $24 \%$ \\
\hline INSERT NON-ELICIT & $68 \%$ & $29 \%$ \\
\hline WIPP & $4 \%$ & $92 \%$ \\
\hline
\end{tabular}


Table 5: Longitudinal distribution of functions: L1 English

\begin{tabular}{|c|c|c|c|c|c|c|c|c|c|}
\hline \multirow{2}{*}{$\begin{array}{l}\text { Trans. } \\
\text { no. } \\
\end{array}$} & \multirow{2}{*}{$\begin{array}{l}\text { Length of } \\
\text { exposure }\end{array}$} & \multirow{2}{*}{$\begin{array}{r}\text { EDIT } \\
(1)\end{array}$} & \multicolumn{2}{|c|}{ META } & \multicolumn{3}{|c|}{ INSERT } & \multirow{2}{*}{$\begin{array}{r}\text { WIPP } \\
(7)\end{array}$} & \multirow[t]{2}{*}{ TOTAL } \\
\hline & & & (2) & (3) & (4) & (5) & (6) & & \\
\hline 01 & $0 ; 0.14$ & 4 & 4 & 1 & 1 & 1 & 10 & & 21 \\
\hline 02 & $0 ; 0.22$ & 2 & 5 & 6 & 10 & 6 & 6 & & 35 \\
\hline 04 & $0 ; 0.29$ & 6 & 6 & 4 & 6 & 11 & 9 & & 42 \\
\hline 05 & $0 ; 1.05$ & 9 & 12 & 10 & 14 & 20 & 28 & & 93 \\
\hline 06 & $0 ; 1.11$ & 5 & 10 & 7 & 13 & 10 & 12 & & 57 \\
\hline 08 & $0 ; 1.25$ & 1 & & 3 & 3 & 2 & & & 9 \\
\hline 09 & $0 ; 2.09$ & 1 & 2 & 9 & 10 & 2 & 6 & & 30 \\
\hline 10 & $0 ; 2.15$ & & 1 & 3 & 4 & 1 & 3 & & 12 \\
\hline 11 & $0 ; 2.22$ & & & 2 & 2 & & & & 4 \\
\hline 12 & $0 ; 3.08$ & 7 & 6 & 9 & 12 & 1 & 13 & & 48 \\
\hline 13 & $0 ; 3.13$ & 2 & 5 & 7 & 9 & 3 & 10 & & 36 \\
\hline 14 & $0 ; 4.03$ & 2 & 1 & 4 & 6 & & 2 & 1 & 16 \\
\hline 15 & $0 ; 4.25$ & & & 1 & 2 & 4 & 2 & & 9 \\
\hline 16 & $0 ; 5.08$ & 1 & 1 & 2 & 2 & 1 & 1 & & 8 \\
\hline 17 & $0 ; 5.15$ & 2 & 2 & 5 & 6 & 1 & 3 & & 19 \\
\hline 18 & 0;6.07 & 1 & 5 & $\mathbf{1}$ & 1 & 2 & 9 & & 19 \\
\hline 19 & $0 ; 6.26$ & 2 & 1 & 2 & 3 & 4 & 17 & & 29 \\
\hline 20 & $0 ; 7.18$ & 1 & 3 & 4 & 5 & 2 & 5 & & 20 \\
\hline 21 & 0;8.03 & 3 & & 3 & 5 & & 2 & & 13 \\
\hline 22 & 0;9.09 & & & & & & 5 & & 5 \\
\hline 23 & $0 ; 9.28$ & & 1 & & 1 & 1 & 5 & & 8 \\
\hline 24 & $1 ; 0.30$ & 1 & & & & & 3 & & 4 \\
\hline 25 & $1 ; 1.18$ & & & 1 & 1 & & 2 & 1 & 5 \\
\hline 26 & $1 ; 2.10$ & 2 & 5 & 3 & 8 & 1 & 2 & & 21 \\
\hline 27 & $1 ; 3.00$ & & & 1 & 2 & & 4 & & 7 \\
\hline 28 & $1 ; 5.10$ & 1 & 1 & & & & 2 & 1 & 5 \\
\hline 29 & $1 ; 5.15$ & & & & & 1 & 9 & & 10 \\
\hline 30 & $1 ; 5.28$ & 1 & 1 & 1 & & & 8 & & 11 \\
\hline 31 & $1 ; 6.16$ & 1 & & & 1 & & 3 & & 5 \\
\hline 32 & $1 ; 7.10$ & 1 & & & 1 & & 1 & & 3 \\
\hline 33 & $1 ; 7.25$ & & & & & & & & \\
\hline 34 & $1 ; 8.15$ & & 1 & 2 & 4 & 1 & 1 & & 9 \\
\hline 35 & $1 ; 9.05$ & 1 & & 1 & 1 & & 4 & & 7 \\
\hline \multirow[t]{2}{*}{ tot } & & 57 & 73 & 92 & 133 & 75 & 187 & 3 & 620 \\
\hline & & 57 & & 165 & & & 395 & 3 & \\
\hline
\end{tabular}


Table 6: Longitudinal distribution of functions: L2 German

\begin{tabular}{|c|c|c|c|c|c|c|c|c|c|}
\hline \multirow{2}{*}{$\begin{array}{l}\text { Trans. } \\
\text { no. }\end{array}$} & \multirow{2}{*}{$\begin{array}{l}\text { Length of } \\
\text { exposure }\end{array}$} & \multirow{2}{*}{$\begin{array}{r}\text { EDIT } \\
(1)\end{array}$} & \multicolumn{2}{|c|}{ META } & \multicolumn{3}{|c|}{ INSERT } & \multirow{2}{*}{$\begin{array}{r}\text { WIPP } \\
(7) \\
\end{array}$} & \multirow[t]{2}{*}{ TOTAL } \\
\hline & & & (2) & (3) & (4) & (5) & (6) & & \\
\hline 01 & $0 ; 0.14$ & 1 & & & 1 & 1 & 6 & 2 & 11 \\
\hline 02 & $0 ; 0.22$ & $\mathbf{1}$ & & & & 1 & 3 & 4 & 9 \\
\hline 04 & $0 ; 0.29$ & & & & & 1 & 3 & 7 & 11 \\
\hline 05 & $0 ; 1.05$ & 2 & & & 4 & 6 & 7 & 6 & 25 \\
\hline 06 & $0 ; 1.11$ & 5 & & & 1 & 1 & 10 & 10 & 27 \\
\hline 08 & $0 ; 1.25$ & & & & 1 & 1 & 3 & & 5 \\
\hline 09 & $0 ; 2.09$ & 2 & & & 2 & 1 & 4 & 1 & 10 \\
\hline 10 & $0 ; 2.15$ & 2 & & & 1 & 1 & & 5 & 9 \\
\hline 11 & $0 ; 2.22$ & & & & & 2 & & 1 & 3 \\
\hline 12 & $0 ; 3.08$ & 1 & & & 2 & 2 & 7 & 10 & 22 \\
\hline 13 & $0 ; 3.13$ & & & & 1 & 3 & 7 & & 11 \\
\hline 14 & $0 ; 4.03$ & & & & 2 & 1 & 13 & 1 & 17 \\
\hline 15 & $0 ; 4.25$ & 2 & & & & & 1 & 2 & 5 \\
\hline 16 & $0 ; 5.08$ & & & & & & 1 & 1 & 2 \\
\hline 17 & $0 ; 5.15$ & & & & 1 & & & 3 & 4 \\
\hline 18 & 0;6.07 & & & & & & 2 & & 2 \\
\hline 19 & $0 ; 6.26$ & & & & & 1 & 3 & 2 & 6 \\
\hline 20 & $0 ; 7.18$ & 2 & & & & 1 & & 2 & 5 \\
\hline 21 & $0 ; 8.03$ & & & & & & 1 & & 1 \\
\hline 22 & $0 ; 9.09$ & & & & & & 1 & & 1 \\
\hline 23 & $0 ; 9.28$ & & & & & & 2 & 2 & 4 \\
\hline 24 & $1 ; 0.30$ & 1 & & & & & 2 & 3 & 6 \\
\hline 25 & $1 ; 1.18$ & 1 & & & & 1 & & & 2 \\
\hline 26 & $1 ; 2.10$ & & & & & & 2 & 1 & 3 \\
\hline 27 & $1 ; 3.00$ & 1 & & & & & & & 1 \\
\hline 28 & $1 ; 5.10$ & 1 & & & & & & 1 & 2 \\
\hline 29 & $1 ; 5.15$ & 2 & & & & & & 1 & 3 \\
\hline 30 & $1 ; 5.28$ & & & & & & & & \\
\hline 31 & $1 ; 6.16$ & & & & & 1 & & & 1 \\
\hline 32 & $1 ; 7.10$ & & & & & & & & \\
\hline 33 & $1 ; 7.25$ & & & & & & & & \\
\hline 34 & $1 ; 8.15$ & & & & & & & & \\
\hline 35 & $1 ; 9.05$ & & & & & & & & \\
\hline \multirow[t]{2}{*}{ tot } & & 24 & & & 16 & 25 & 78 & 65 & 208 \\
\hline & & 24 & & & & & 119 & 65 & 208 \\
\hline
\end{tabular}


Table 7: Longitudinal distribution of functions: other L2s

\begin{tabular}{|c|c|c|c|c|c|c|c|c|c|}
\hline \multirow{2}{*}{$\begin{array}{l}\text { Trans. } \\
\text { no. } \\
\end{array}$} & \multirow{2}{*}{$\begin{array}{l}\text { Length of } \\
\text { exposure }\end{array}$} & \multirow{2}{*}{$\begin{array}{r}\text { EDIT } \\
(1)\end{array}$} & \multicolumn{2}{|c|}{ META } & \multicolumn{3}{|c|}{ INSERT } & \multirow{2}{*}{$\begin{array}{r}\text { WIPP } \\
(7)\end{array}$} & \multirow[t]{2}{*}{ TOTAL } \\
\hline & & & (2) & (3) & (4) & (5) & (6) & & \\
\hline 01 & $0 ; 0.14$ & & & & & & 2 & & 2 \\
\hline 02 & $0 ; 0.22$ & & & & & & 1 & & 1 \\
\hline 04 & $0 ; 0.29$ & 1 & & & & 1 & & & 2 \\
\hline 05 & $0 ; 1.05$ & & & & & & & 1 & 1 \\
\hline 06 & $0 ; 1.11$ & & & & & & & & \\
\hline 08 & $0 ; 1.25$ & & & & 1 & 2 & & & 3 \\
\hline 09 & $0 ; 2.09$ & & & & & & & 2 & 2 \\
\hline 10 & $0 ; 2.15$ & & & & & & 2 & & 2 \\
\hline 11 & $0 ; 2.22$ & & & & & & & & \\
\hline 12 & $0 ; 3.08$ & & & & & & & & \\
\hline 13 & $0 ; 3.13$ & & & & & & 1 & & 1 \\
\hline 14 & $0 ; 4.03$ & & & & & & & & \\
\hline 15 & $0 ; 4.25$ & & & & & & & & \\
\hline 16 & $0 ; 5.08$ & & & & & & & & \\
\hline 17 & $0 ; 5.15$ & & & & & & 1 & & 1 \\
\hline 18 & $0 ; 6.07$ & & & & & & & & \\
\hline 19 & $0 ; 6.26$ & & & & & & & & \\
\hline 20 & $0 ; 7.18$ & & & & & & & & \\
\hline 21 & $0 ; 8.03$ & & & & & & & & \\
\hline 22 & 0;9.09 & & & & & & & & \\
\hline 23 & $0 ; 9.28$ & & & & & & & & \\
\hline 24 & $1 ; 0.30$ & & & & & & & & \\
\hline 25 & $1 ; 1.18$ & & & & & & & & \\
\hline 26 & $1 ; 2.10$ & & & & & & & & \\
\hline 27 & $1 ; 3.00$ & & & & & & & & \\
\hline 28 & $1 ; 5.10$ & & & & & & & & \\
\hline 29 & $1 ; 5.15$ & & & & & & & & \\
\hline 30 & $1 ; 5.28$ & & & & & & & & \\
\hline 31 & $1 ; 6.16$ & & & & & & 1 & & 1 \\
\hline 32 & $1 ; 7.10$ & & & & & & & & \\
\hline 33 & $1 ; 7.25$ & & & & & & & & \\
\hline 34 & $1 ; 8.15$ & & & & & & & & \\
\hline 35 & $1 ; 9.05$ & & & & & & & & \\
\hline \multirow[t]{2}{*}{ tot } & & 1 & & & 1 & 3 & 8 & 3 & 16 \\
\hline & & 1 & & $\mathbf{0}$ & & & 12 & 3 & 16 \\
\hline
\end{tabular}


Table 3a: List of items in WIPP switches and similarity of their counterparts in Swedish

\begin{tabular}{|c|c|c|c|c|}
\hline & \multicolumn{2}{|c|}{ SIMILAR IN FORM } & \multicolumn{2}{|c|}{ NOT SIMILAR IN FORM } \\
\hline & item & Swedish equiv. & item & Swedish equiv. \\
\hline L1 ENGLISH & even & även & the & den \\
\hline L2 GERMAN & $\begin{array}{l}\text { da } \\
\text { dann } \\
\text { der } \\
\text { die } \\
\text { ein } \\
\text { konn- } \\
\text { mit } \\
\text { ob } \\
\text { so } \\
\text { waren } \\
\text { was } \\
\text { wer } \\
\text { wir } \\
\text { wir müss- } \\
\text { be-(wertet) } \\
\text { hier } \\
\text { wein } \\
\text { frei-(tag) } \\
\text { ging } \\
\text { plötzlich } \\
\text { studen- } \\
\text { typ-(isch) } \\
\text { wohnt- }\end{array}$ & $\begin{array}{l}\text { där } \\
\text { då } \\
\text { den } \\
\text { den } \\
\text { en } \\
\text { kunde } \\
\text { med } \\
\text { om } \\
\text { så } \\
\text { var } \\
\text { vad } \\
\text { vem } \\
\text { vi } \\
\text { vi måste } \\
\text { bevärda (IL form: } \\
\text { Sw. = värdera) } \\
\text { här } \\
\text { vin } \\
\text { fredag } \\
\text { gick } \\
\text { plötsligt } \\
\text { student } \\
\text { typisk } \\
\text { bodde } \\
\text { (cf. Sw. våning) }\end{array}$ & $\begin{array}{l}\text { am } \\
\text { das } \\
\text { er } \\
\text { es } \\
\text { ihr } \\
\text { ni-(cht) } \\
\text { und } \\
\text { wie } \\
\\
\\
\text { gut } \\
\text { klei- } \\
\text { vielleicht } \\
\text { ze-(hn) }\end{array}$ & $\begin{array}{l}\text { på } \\
\text { det } \\
\text { han } \\
\text { det } \\
\text { hennes } \\
\text { inte } \\
\text { och } \\
\text { hur } \\
\\
\text { bra } \\
\text { lille } \\
\text { kanske } \\
\text { tio }\end{array}$ \\
\hline OTHER L2s & un & en & comment & hur \\
\hline
\end{tabular}

